\title{
THE EVOLUTION OF SEX DIFFERENCES IN TOOL USE
}

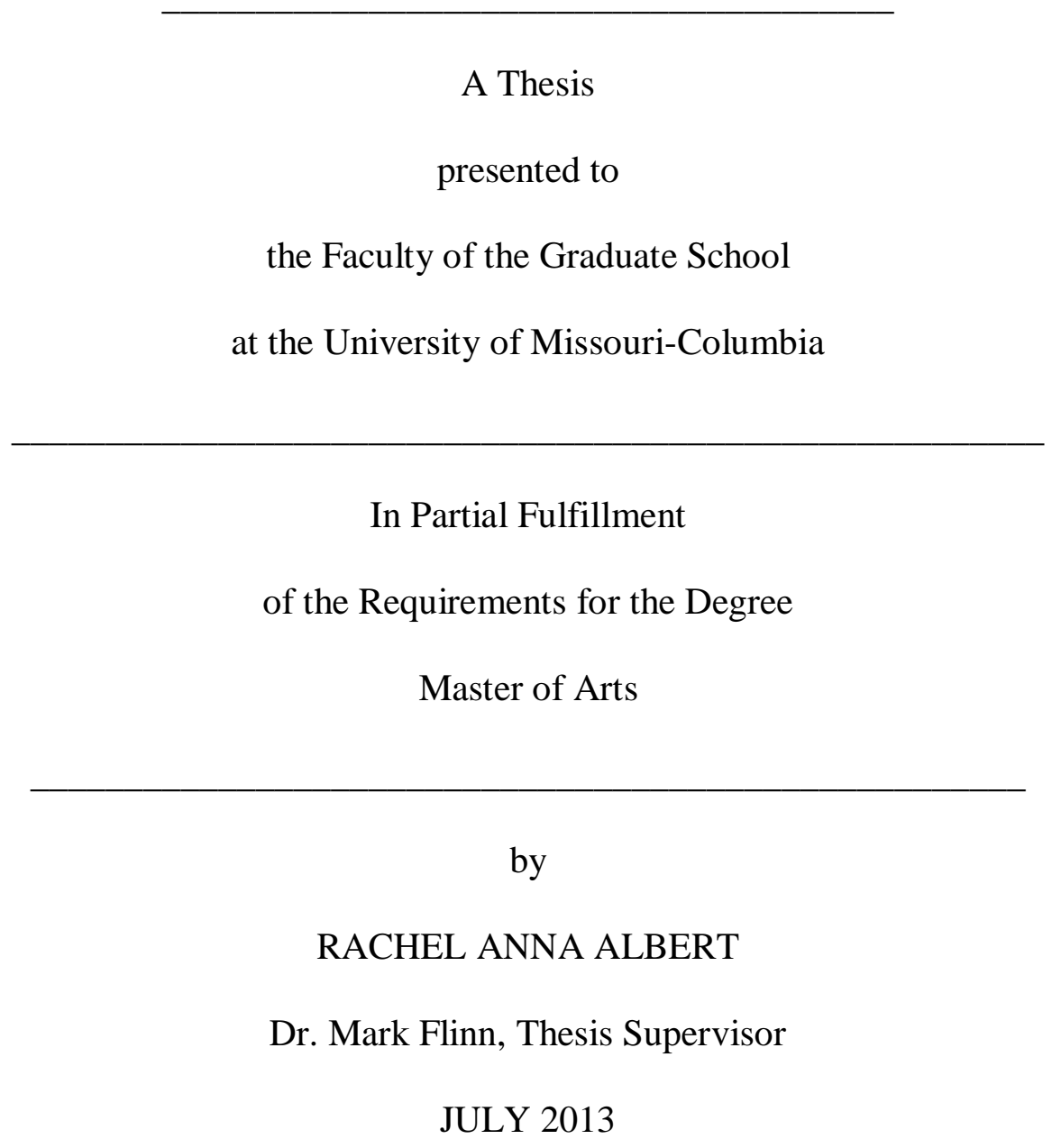


The undersigned, appointed by the dean of the Graduate School, have examined the thesis entitled

\section{THE EVOLUTION OF SEX DIFFERENCES IN TOOL USE}

presented by Rachel Albert, a candidate for the degree of Master of Arts, and hereby certify that, in their opinion, it is worthy of acceptance.

Professor Mark Flinn

Professor Gregory Blomquist

Professor Denis McCarthy 


\section{ACKNOWLEDGEMENTS}

I would like to thank Dr. Mark Flinn for advising me throughout this process. To Dr. Greg Blomquist for providing feedback, support, and significant assistance with statistical analysis. To Dr. Denis McCarthy for providing feedback and support. To Dr. Todd VanPool for his help in generating the idea for this paper, as well as for providing support and guidance throughout the process of writing it. To Dr. Lee Lyman for

providing support and guidance. To Robin Yim and Whitney Coffey, my fellow graduate students, for providing an immense amount of support, feedback, guidance, and encouragement. 


\section{TABLE OF CONTENTS}

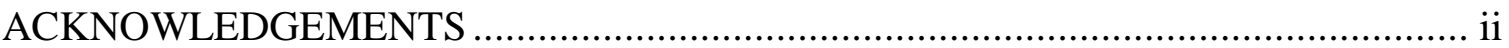

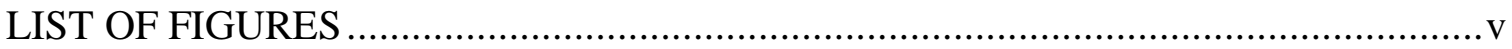

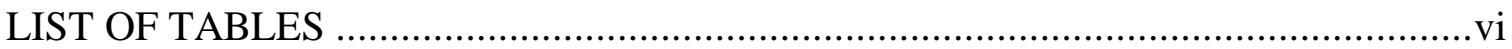

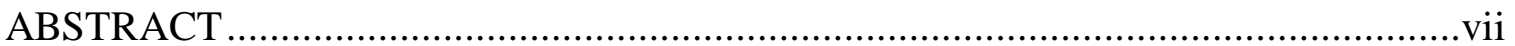

\section{Chapter}

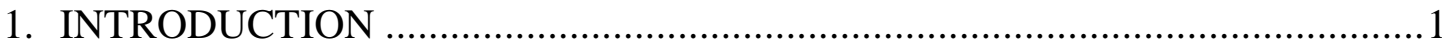

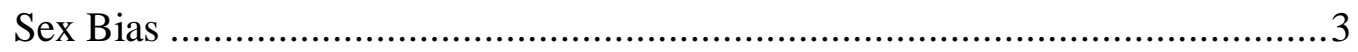

The Present Study ......................................................................................

2. METHODS

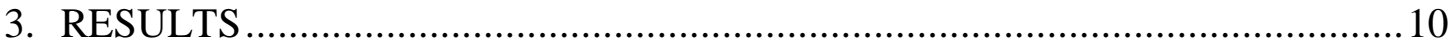

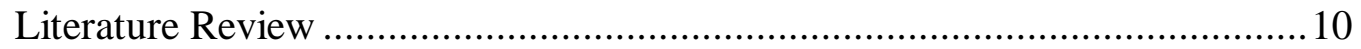

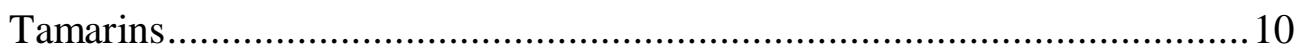

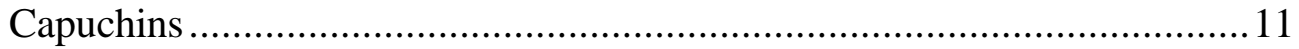

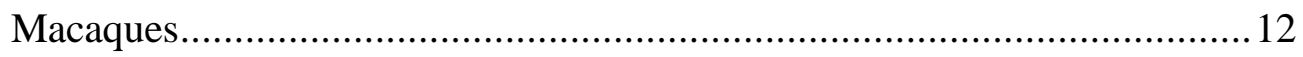

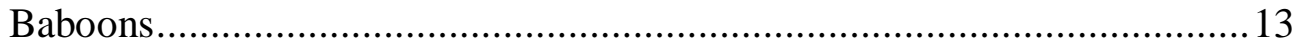

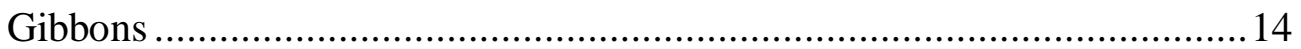

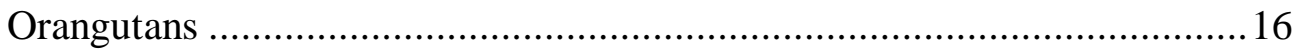

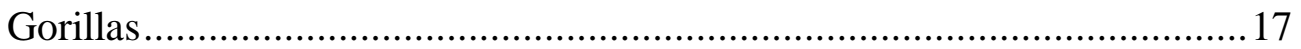

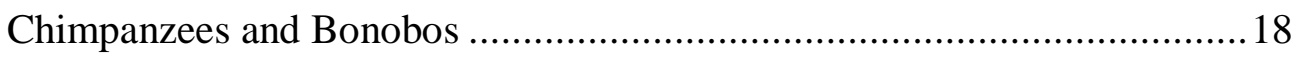

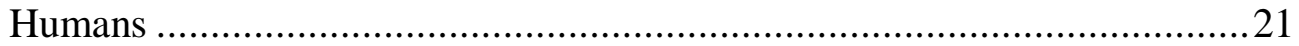


Non-Primate Species.

Dolphins

Otters

Corvids .............................................................................. 25

Overall Analysis .............................................................................. 27

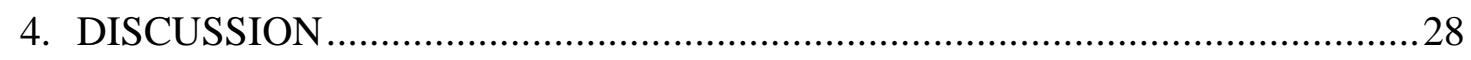

APPENDIX

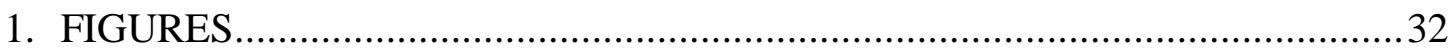

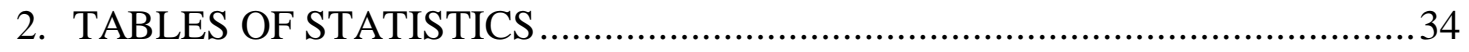

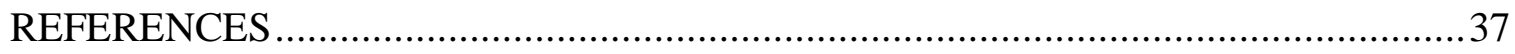




\section{LIST OF FIGURES}

Figure 1. The relationship between body mass and basal metabolic rate (BMR). Points above the line indicate higher BMR than expected for body mass, and points below the line indicate lower BMR than expected for body mass.

Figure 2. Comparison of male and female energetic cost of reproduction. Points above the line indicate higher female energetic costs, and points below the line indicate higher male energetic costs. 


\section{LIST OF TABLES}

Table 1. Mean residuals and t-test results for female and no tool use bias species for body mass versus BMR. Bonobos, capuchins, and gorillas have been omitted.

Table 2. Mean residuals and one-way ANOVA results across tool use bias species for male versus female energetic costs of reproduction. Corvids have been omitted.

Table 3. Basal metabolic rate (BMR), tool use bias, daily energy expenditure (DEE), cost of reproduction (COR), and body mass data for the thirteen species of interest. Tool use bias is indicated as female $(\mathrm{F})$, male $(\mathrm{M})$, or none $(\mathrm{N})$. Missing data (BMR and COR) are indicated by N/A. 


\title{
THE EVOLUTION OF SEX DIFFERENCES IN TOOL USE
}

Rachel Albert

Dr. Mark Flinn, Thesis Supervisor

\begin{abstract}
Tool use is no longer a defining characteristic of humans - other primates are proficient tool users (e.g. chimpanzees), but several non-primate species are competent tool users and manufacturers as well. Sex differences in tool use have not been well studied, though there has been significant research interest in other behavioral sex differences. A literature review of tool use in ten species of primates (including humans) and three non-primate species (corvids, dolphins, and otters) revealed that bonobos, chimpanzees, and dolphins have more proficient female tool users than male, and that capuchin males are more proficient tool users than females. Ecological factors do not fully explain sex bias in tool use; female-biased species appear to have evolved tool use under sociocultural selective pressures. Several species have the cognitive capacity to use tools but do not use them in the wild, indicating that intelligence alone cannot drive the evolution of tool use.
\end{abstract}




\section{INTRODUCTION}

Tool use is such an integral part of our daily lives that it is easy to forget that our species is one of very few that engage in such behaviors. Darwin (1871/1952) proposed that tool use drove the expansion of the brain and evolution of human intelligence:

...if some one man in a tribe, more sagacious than the others, invented a new snare or weapon, or other means of attack or defence... [it] would prompt the other members to imitate him; and all would thus profit. The habitual practice of each new art must likewise in some slight degree strengthen the intellect...If such men left children to inherit their mental superiority, the chance of the birth of still more ingenious members would be somewhat better, and in a very small tribe decidedly better. [Darwin 1871/1952:321]

Though some other primates are skilled tool users (and, more rarely, manufacturers), one of the defining characteristics of human tool use is the modification of raw materials into suitable tools - most tool-using primates are adept at choosing the appropriate piece of readily available stone or wood for a given task, but rarely make modifications. The complexity and diversity of the implements humans manufacture and use is much greater than those of our closest living relatives, chimpanzees and bonobos. However, we are far from having a complete understanding of the evolution of tool use in humans and other species.

In addition to nonhuman primates, several cases of tool use in non-primate species have been reported, indicating that tool use may not require a large primate brain. Brown (2012) has documented some potential evidence for tool use in a few species of 
fish - larger fish have been observed using anvils to crack open bivalves, cichlids and other smaller fish "glue" their eggs to leaves for easier transport, and several species appear to use water as a tool to clear detritus from a potential nest area or dislodge prey. Considering the small brain size of fish and their lack of grasping appendages, it appears that rather than being a case of convergent evolution, tool use evolved independently several times. Male spotted bowerbirds build elaborate bowers (attractive nests) to attract females, and male reproductive success is strongly correlated with the overall quality and decoration of the bower. Some male bowerbirds have even been observed stealing decorations from or destroying parts of other males' bowers, emphasizing the importance of this tool use as a sexual display (Borgia \& Mueller 1992).

Of course, the interpretation of these reports depends upon which definition of tool use one uses - Beck (1980:10) defined tool use as:

...the employment of an unattached environmental object to alter more efficiently the form, position, or condition of another object, another organism, or the user itself when the user holds or carries the tool during or just prior to use and is responsible for the proper and effective orientation of the tool [as cited in Breuer et al. 2005: 2041].

Beck also described six different modes of nonhuman primate tool use: 1 . throwing objects at predators or rivals to threaten them, 2. using objects defensively (usually hitting predators or rivals), 3. using objects as hunting implements (only hominids), 4 . incorporating objects into social displays, 5 . using objects to clean body parts, and 6 . using or making objects to acquire food (usually insects or nuts) (Beck 1980 as cited in van Schaik et al. 1999). Beck (1980) presumed the first and second of these modes to be the oldest types of tool use from which all others are derived - nearly all primates engage 
in some kind of predator or rival-deterrent behavior, and it requires no modification of the tool. Chimpanzees engage in many social display behaviors (the fourth mode of tool use), including shaking branches and leaf clipping (van Schaik et al. 1999). The sixth type of tool use has been proposed as the most important type in hominid evolution - van Schaik et al. (1999) researched the conditions favoring the evolution of hominid tool use, and they described four reasons why feeding tools are the probable ancestor of other forms of tool use. They noted that 1 . Feeding tools considerably contribute to fitness in current preagricultural people, 2. Population-wide tool use and manufacture is found only in the hominoid clade (great apes and hominids), 3. The majority of the tools found at hominid sites are presumed to be involved in food processing, and 4. Compared to other tools used by nonhuman primates, feeding tools are more likely to require modification, and great apes learn to use feeding tools via social learning (similar to humans). Sex Bias

One neglected area of research in tool use is sex differences; the idea of "man the toolmaker" (Oakley 1957) has been doubly refuted by multiple studies of other primates - females often use tools more frequently and are more skilled in their use (McGrew 1992). It has been demonstrated that the sexes differ in many species in physical and behavioral characteristics, so it should not be surprising that they might differ in tool use (and that different selective pressures have shaped their tool use behaviors). Several theories may explain sex bias in tool use. Wrangham (1980) proposed a model of femalebonded primate groups, and the ecological conditions under which one might expect them to form. He described three criteria for identifying a female-bonded primate group: females breeding in their natal group, males transferring between groups, and the presence of 
"differentiated and consistent female relationships based on grooming, aiding, huddling or dominance interactions" (Wrangham 1980:266). He identified twenty-five species that fit these criteria, including white-throated capuchins, several species of macaques, and several species of baboons. Chimpanzees, mountain gorillas, and Hamydras baboons were given as examples of non-female-bonded species. He suggests that cooperation between females in these groups are beneficial during foraging when good feeding sites exist in discrete, defensible patches, and when food patches are large enough to satisfy the caloric needs of all group members. The model also proposes that in territorial species, males in female-bonded groups will be scarce, while males should be plentiful in non-territorial female-bonded groups.

Wrangham noted five key behavioral differences between female-bonded (FB) and nonfemale-bonded (NFB) species: 1. Importance of food patches in inter-group interactions (FB high, NFB low), 2. Frequency of female participation in inter-group interactions (FB high, NFB low), 3. Female role in group movements (FB active, NFB passive), 4. Frequency of female-female grooming (FB high, NFB low), and 5. Frequency of male-male grooming in multi-male groups (FB low, NFB high) (Wrangham 1980:286). Wrangham was referring to female social support in this quote, but it seems applicable to the puzzle of some female bias in tool use: "If breeding females have a uniquely cost-effective resource, a strategy adapted to acquiring it will have uniquely large effects of increasing female reproductive success" (Wrangham 1980:264). Females in female-bonded groups may have sociocultural selective pressures to develop tool use, and are probably more likely to learn such behaviors from and pass them along to other females.

Another set of explanations about the conditions under which primate tool use evolved comes from van Schaik et al. (1999). The authors tested four predictions: 1. Species capable of dexterous manipulation should be extractive foragers (i. e. crack open 
nuts or seeds, "fish" for insects in mounds), 2. Species that use feeding tools in the wild should display manual dexterity, 3. Intelligent species should be the only ones to show population-wide tool use and manufacture in the wild, and 4. Social tolerance should correlate with widespread tool use in a population (social tolerance is expected to be correlated with exploratory behavior, invention, and sometimes gregariousness). They found some support for the first two hypotheses (they were necessary but not sufficient to lead to the evolution of tool use), but the last two appeared to be most important. Their social tolerance theory may be especially useful in explaining widespread tool use - most of the species that use tools in the wild display behavior that supports this theory (van Schaik et al. 1999). The authors propose that tool use is a byproduct of intelligence, rather than a driving force in the evolution of intelligence.

The presence of sex differences in costs of reproduction may help explain sex bias in tool use. Trivers (1972) proposed that sexual selection has led to disparities in the costs of reproduction in most primate species, meaning that females generally bear greater energetic costs to reproduction. These costs include gestation, lactation, and postnatal care, all of which require females to increase their caloric intake (and to provide food for older offspring). Only when male primates are more than 60 percent larger than their female counterparts do the costs of maintaining a large body lead to males having greater energetic requirements (Key \& Ross 1999). As breeding females in many primate species have greater energetic demands than males, one might thus expect them to exploit any possible resource to fulfill those requirements. Obviously both sexes should be motivated to exploit high-quality food sources with the least amount of effort, but the fitness benefits to tool use may differ between the sexes. It may be more advantageous for males to use tools for social displays or intrasexual competition, while it may be more advantageous for females (especially those in female-bonded primate groups) to use tools 
for obtaining food. When these factors are taken together (unequal costs of reproduction leading to greater daily caloric requirements for females, who should exploit a greater range of food resources than males), it might be expected that females would more capable tool users in many species.

\section{The Present Study}

Most research has also focused on one species or a comparison between a few closely-related species, rather than comparing tool use across a wide range of species. In this paper, the author has examined sex differences in tool use in humans, other primates, and non-primates by conducting a literature review of previous research to examine the evolution of tool use across thirteen species groups rather than in a single species. The species that have been examined include tamarins, capuchins, macaques, gibbons, baboons, orangutans, gorillas, chimpanzees, bonobos, humans, dolphins, otters, and corvids. Examining non-primate species may help to answer the question of whether tool use drove the evolution of human intelligence as Darwin (1871/1952) implied, or whether tool use should be viewed as a byproduct of intelligence. In addition to sex bias in tool use, costs of reproduction, body size sexual dimorphism, and basal metabolic rate (BMR) in these species were studied. By studying costs of reproduction and body size sexual dimorphism, the theories presented by Trivers (1972) and Key \& Ross (1999) can be tested. In addition, studying BMR will help clarify whether sex bias in tool use evolved due to ecological, cognitive, or sociocultural pressures (Wrangham 1980, van Schaik et al. 1999).

BMR was studied to control for varying metabolic rates in the animals of interest. $\mathrm{BMR}(\mathrm{kJ} /$ hour) increases as body mass increases, but the rate is negatively allometric 
(McNab 2008). Though they have a smaller net caloric requirement, endothermic animals with smaller body masses have higher metabolic rates than larger animals (with all other variables held constant). However, the precise relationship between increasing body mass and decreasing metabolic rate is debated - there is mixed evidence for $\mathrm{B} \propto \mathrm{M}^{3 / 4}$ or $\mathrm{B} \propto$ $\mathrm{M}^{2 / 3}$ (where $\mathrm{B}=$ body mass and $\mathrm{M}=$ metabolic rate) (Dodds, Rothman, \& Weitz 2001). 


\section{METHODS}

Data were collected from previous studies on the thirteen species (or groups of species, such as corvids) of interest. Tool use sex bias was rated as female, male, or none according to the descriptions of observations and statistical tests provided by the authors of the studies included in the literature review. When no discernible pattern of sex bias was detected (i.e. no strong male or female bias), the species was categorized as having no bias. BMR (kJ/h) data were taken from McNab (2008) (chimpanzees, dolphins, humans, and otters), McNab (2009) (corvids), and Ross (1992) (baboons, gibbons, orangutans, and tamarins). BMR data were not available for bonobos, capuchins, or gorillas, so they were excluded from analysis. Cost of reproduction data were taken from Key \& Ross (1999) (chimpanzees, gorillas, gibbons, orangutans), Furuichi et al. (1998) (bonobos), Mann et al. (1999) (dolphins), Lemasson et al. (2008) (baboons), Lee (1979) (humans), Monson et al. (2000) (otters), Gomendio (1990) (macaques), and Savage et al. (1997) (tamarins). Corvids were excluded from the cost of reproduction calculations, as the equations used included gestation and lactation (which is not comparable in nonmammals). Costs of reproduction for each sex were calculated using the equations presented in Key \& Ross (1999): $E_{\mathrm{M}}=\mathrm{DEE} \times T_{\mathrm{ibi}}$ (where $E_{\mathrm{M}}$ is the male energy expenditure per female reproductive event (kcal), DEE is daily energy requirement, and $T_{\mathrm{ibi}}$ is interbirth interval (days) $)$, and $E_{\mathrm{F}}=\operatorname{DEE}\left(\left(T_{\text {gest }} \times 1.25\right)+\left(T_{\text {lact }} \times 1.5\right)+\left(T_{\mathrm{ibi}}-T_{\text {gest }}-\right.\right.$ $\left.T_{\text {lact }}\right)$ ) (where $E_{\mathrm{F}}$ is the female energy expenditure per reproductive event (kcal), $T_{\text {gest }}$ is gestation length (days), and $T_{\text {lact }}$ is lactation length (days)). Daily energy expenditure 
(DEE) was also calculated using the equation presented in Key \& Ross (1999): $\log \mathrm{DEE}=$ $0.75 \log W+1.97$ (where $W=$ body mass $(\mathrm{kg}))$.

Data about the !Kung San were used to calculate human reproductive costs (in spite of their relatively small stature) because they 1 . Are preagrarian, 2. Make and use the majority of their tools for food extraction and processing, similar to other primates, and 3. Have had their daily lives extensively studied, making them an excellent case study for this paper. Statistical analyses (bivariate regressions, least squares residuals, and t-test, and one-way ANOVA) were performed using R (R Development Core Team 2011). 


\section{RESULTS}

\section{Literature Review}

Tamarins. Tamarins have not been observed using tools in the wild, but they have been successfully taught to use tools to acquire food in a manner similar to that of other primates. Hauser (1997) experimented with four male and five female cottontop tamarins, and found that males took an average of 5.25 trials to reach criterion ( $85 \%$ successful use of a cane-shaped tool to bring a food pellet within reach), while females took an average of 10 trials. Hauser et al. (2002) conducted the same experiment with six (three male, three female) infant cottontop tamarins (ranging from 4 to 12 months of age at testing) and found that males took an average of 10.7 trials to reach criterion, while females took 12.7 trials. The author did not analyze the data for sex differences, so it is unclear whether males are more proficient tool users than females.

Stoinski \& Beck (2001) documented spontaneous tool use in captive golden lion tamarins over a period of 3750 hours. Their results are a bit puzzling, as they found one mate pair that was especially proficient at tool use. The male in the pair was a more prolific tool user (he used tools for foraging and grooming daily, and chewed antennae to bend them into a better shape for grooming), but both individuals far surpassed the other tamarins in quantity and quality of tool use. The female was observed using twigs for foraging 14 times, and she used twigs and antennae 12 times each for grooming. The next 
most proficient tamarin (male) was observed using twigs and antennae for foraging at least once weekly, but all the others were observed using tools fewer than 4 times throughout the entire observation period. Again, the authors did not conduct statistical tests, so no definitive sex bias is apparent.

Capuchins. Spagnoletti et al. (2011) studied stone tool use in fifteen (seven male, eight female) wild bearded capuchin monkeys and found that males used stone tools to crack nuts five times more frequently than females, which the authors attributed to males' larger body sizes and biomechanical advantage over females (males can manipulate large hammerstones, are able to lift the hammerstone higher, and can add extra force in the downward stroke). The authors found that males used tools to crack significantly more nuts than females (median (interquartile range, IQR): 130 (87.5) and 27 (29), respectively; Mann-Whitney, $\left.U=8, n_{m}=7, n_{f}=8, \mathrm{p}<0.05\right)$. Females also often used hammerstones that weighed 44-52 percent of their body weights, while males used hammerstones that only weighed $24-40$ percent of their body weights; the hammerstones the males chose were still 100 grams heavier on average than those chosen by females, accentuating the finding that it is much more advantageous for males to spend time and energy cracking nuts than females. Females were also far less likely to crack highresistance (difficult to open) nuts than males - both sexes were equally likely to crack low-resistance nuts, demonstrating that females are only willing to exert energy to crack nuts that they will be almost guaranteed to be able to open. Interestingly, females were more likely to choose heavier hammerstones when attempting to crack high-resistance nuts than males. Overall, the authors (Spagnoletti et al. 2011) found that males used tools 
more frequently than females, and that larger individuals of both sexes were more skilled tool users than smaller individuals.

Moura \& Lee (2010) observed ten wild bearded capuchins (four male, six female) and found that males are also more likely to use probing and digging tools to obtain food than females (Kruskal Wallis, $H=13.31, \mathrm{df}=2, \mathrm{p}=.001$ ). Again, males used heavier stone tools than females for digging, and males exhibited probing behaviors almost exclusively (only one female was observed probing). Digging was the most common behavior necessitating tool use observed in both sexes, which may be due to the high caloric value of tubers; i.e., the energy expenditure to manipulate a relatively heavy stone tool would be less than the reward of high-energy foods for females. The authors also proposed that extensive tool use by males may indicate provisioning and paternal investment, as females and juveniles were often in close proximity to males engaging in tool use (and subsequently scavenged any resulting food).

Macaques. Gumert et al. (2011) observed stone tool use to open shelled foods in seventy Burmese long-tailed macaques and found a somewhat unclear trend. While females used more tools overall than males during feeding ( 72 percent of the time versus 53 percent of the time; independent $t$ test: $t=-3.819$, df $=282, p<.001$ ), they did not appear to be more skilled tool users than males. Females were found to use stone tools to open sessile (attached) oysters more often, while males were found to use stone tools to open unattached shelled foods. Different types of food also require different techniques to open them, leading to additional sex differences. Sessile foods require an axing motion to chip them open (requiring a precision grip), while unattached foods are generally 
transported to an anvil and pounded with a hammerstone (requiring a power grip); smaller tools are also used more often for sessile foods, while larger tools are more useful for unattached foods. Therefore, females are more proficient with smaller tools and using an axing motion $(t=-6.104, \mathrm{df}=186, p<.001)$ while males are more proficient with larger tools and using a pounding motion $(t=8.413, \mathrm{df}=186, p<.001)$. The authors also found that males were more successful and faster at opening unattached foods, though females were successful as well (males were 94 percent successful while females were 80 percent successful); however, there were no sex differences in the number of food items successfully cracked in a given feeding session. Thus, there does not appear to be a sex bias in tool use for macaques.

Baboons. Baboons are not known to commonly use tools, though they have been observed using them in the wild. van Lawick-Goodall et al. (1973) noted two olive baboons using objects to wipe at their mouths - a female used a stone to rub dried juice from her mouth, and a male used an old maize kernel to wipe blood from his mouth. Beck (1973) conducted an experiment with captive hamydras baboons to determine whether they would cooperatively use tools; he found that a pair of baboons who had been mating with each other successfully cooperated to gain a food reward. The female learned to pass the tool (an L-shaped steel rod) to the male in another cage, which he used to bring a pan full of highly preferred fruits and vegetables within his reach (and both animals were able to eat from it). The food pan was out of the female's reach even with the tool, so the only way she could attain the food was through cooperation with the male. 
One of the few studies reporting sex differences in baboon tool use was conducted by Westergaard (1992). The author presented five (three male, two female) infant (6-8 months of age) with various tools for obtaining food or water (probes, sponges, cups, and plastic pipes to be used as drinking straws) and observed their activity. He found mixed results with respect to sex differences - with some tools, the females were able to gain the food reward with a higher rate (sponges) or total frequency (cups, drinking straws), and with other tools, the males were more successful overall (probes) or used them at a higher total frequency (sponges). There was also variation in the number of tests each baboon was exposed to - one female was only tested once, while two of the males were tested three times (the other two females and one male were each tested twice). The author did not perform statistical tests on the data, but there does not appear to be a sex difference.

Gibbons. Cunningham et al. (2006) conducted a study in which hoolock gibbons (three male, two female) had to manipulate a rake tool to obtain food while simultaneously avoiding a trap into which the food reward could fall. The authors found that male gibbons were more successful at the outset but didn't improve over time, while females lagged in the beginning but quickly caught up to the males. The authors did not conduct statistical tests to detect sex differences, but their results did not seem to indicate a sex bias in tool use. The authors also found that gibbons of both sexes were more successful than chimpanzees or capuchins at avoiding the trap in their second experiment. The gibbons were given a choice between two rakes to pull to obtain the food, one of which would pull the food into the trap while the other would bring the food within 
reach. The authors hypothesized that the gibbons may have been using a simple associative rule to solve the puzzle (pulling the left rake always gets food) rather than a more complex representational strategy that other primates may use.

Cunningham et al. (2011) found that even though gibbons have not been observed using tools for food acquisition in the wild, they seem to be able to recognize useful features in potential tools. The authors hypothesized that this effect would be magnified by prior exposure to the tool (and thus, learning about its potential usefulness). They examined twenty-two hoolock gibbons (ten male, twelve female) and found a sex difference in the effect of prior exposure on the time needed to obtain a food reward (a grape or raisin placed out of reach) using the tool (a rake-shaped object). Female gibbons obtained the food reward significantly faster with prior exposure than without (ANOVA: $F(1,5)=7.298, p=.043)$. Females gibbons took less time to make contact with the tool both with and without prior exposure (and so appeared to be more interested in them), but took much longer than males to successfully obtain the food reward without prior exposure (194.0 seconds for no-exposure females versus 66.25 seconds for no-exposure males). Male gibbons actually took more time to make contact with the tool when they had had prior exposure to it, but their time to successfully obtaining the food was the same regardless of prior exposure (66.25 seconds without exposure, and 67.50 seconds with prior exposure). Interestingly, prior exposure to the tool decreased the time it took for females to obtain the food from 194.0 seconds to 67.50 seconds (the same as males). Thus, it appears that the females were more interested in the tool (females took an average of 17.65 seconds to make contact with it, while no-exposure males took 40.25 
seconds and prior exposure males took 127.0 seconds) and learned more from previous exposure to its potential usefulness, but males were naturally better at using the tool. The authors did not find significant differences between the sexes in time to obtain the food reward, so it does not appear that gibbons have a sex bias in tool use.

Orangutans. Spontaneous tool modification and use was reported by Nakamichi (2004) in captive group-living Sumatran orangutans (Pongo pygmaeus abelii) composed of three females and one male at an artificial termite mound (the holes were filled with mustard, barbeque sauce, applesauce, or peanut butter rather than termites). The author found that the male orangutan was significantly more likely than the females to select new branches which would require modification before using as tools than sticks that had been previously modified $(\mathrm{p}<.05$ on a binomial test). The female orangutans were equally likely to select a new branch or an old stick, and both sexes were proficient at stripping leaves from new branches so that the branches could be inserted into the termite mound to obtain food. The adult female was significantly better than the adult male at producing "good tools" (branch with several leaves left at the proximal end, which improves grip) $\left(X^{2}=16.36, p<.01\right)$, and the females together were more successful at using tools to fish food out of the termite mound than the male $\left(X^{2}=14.26, p<.01\right)$. The adult female also created a "special tool" by chewing the distal end of a branch, effectively turning the end into a sponge. The spongy end of the tool was especially effective at drawing food out of the hole, and the adult female was able to suck more liquid off of the sponge than an unmodified stick. Since the sample size is so small, it is difficult to conclude sex bias in orangutans (in spite of significant differences). This study 
demonstrates that orangutans have the cognitive capacity to both make and use tools, though it is limited due to sample size and the fact that the animals were in captivity.

Osvath \& Osvath (2008) found that orangutans, like chimpanzees, are also capable of delaying immediate gratification and planning for the future, which demonstrates the cognitive capacity for mental time travel. Both apes were also demonstrated to be capable of generalizing the functionality of a novel tool for future use. The capacity for such forethought had not been previously demonstrated, and it was assumed to be a unique trait of humans in the primate lineage (though it has been demonstrated that corvids and several species of rodents also have such a capacity) (Osvath \& Osvath 2008).

Gorillas. Tool use in gorillas has not been given much research attention, and unlike other primates, their tool use does not seem to be focused on food acquisition. However, a few authors have documented their observations of tool use in two different subspecies of gorilla. Breuer et al. (2005) observed wild western gorillas (Gorilla gorilla gorilla) while Wittiger \& Sunderland-Groves (2007) observed Cross River gorillas (Gorilla gorilla diehli) engaging in a few tool use behaviors. Breuer et al. reported that two female gorillas used detached branches as postural supports, once as a combination walking stick and water depth tester while crossing an elephant pool, and another as a stabilizer while crushing food (the gorilla shoved the branch in the swampy ground and held it with one hand while she squatted and crushed food with the other) and later as a bridge across swampy ground (she placed it horizontally on the ground and crossed quadrupedally over it). 
Wittiger \& Sunderland-Groves (2007) witnessed thirteen gorillas incorporating tool use into agonistic displays against humans. In one instance, several adults threw fistfuls of grass towards a group of human researchers (clearly aimed towards the humans); in another, a sub-adult threw a detached branch towards the researchers; in a third, several gorillas engaged in a grass-throwing fight with a passing man. It appears tool use for feeding has not been selected for in gorillas to the same extent as other primates because gorillas have food which is does not require much extraction or nondigestive processing to obtain, possibly making the energy and time expenditure for tool use too costly. Neither of the aforementioned studies (Breuer et al. 2005, Wittiger \& Sunderland-Groves 2007) conducted statistical tests to determine sex differences, though the small sample sizes make it highly unlikely that significant differences would have been found. Therefore, it is unclear whether gorillas have a sex bias in tool use.

Chimpanzees and Bonobos. Chimpanzees are known to be skilled tool users various groups have mastered the hammer and anvil technique, use stone tools on hard nuts and wooden tools on softer nuts, pass tool use techniques through both vertical and horizontal cultural transmission, and have developed hunting and insect fishing tools (Watts 2008). It has been demonstrated in several studies that female chimpanzees are much more accomplished and frequent tool users than male chimpanzees (McGrew 1992, Boesch \& Boesch, 1990). For example, Boesch \& Boesch (1990) found that females use tools more successfully to eat ants $\left(2 \times 2\right.$ contingency table, $\left.X^{2}=6.90, p<.01\right)$ in the Tai forest. Chimpanzees are skilled at recognizing the appropriate tool for a given task, but rarely modify raw materials into tools. One notable exception to this pattern is the 
formation of thrusting spears for hunting nocturnal bush babies, which spend their days in holes in trees. Chimpanzees have been observed deliberately sharpening sticks using their teeth, then thrusting them into the holes in the trees with much greater force than used for termite fishing. Interestingly, females have been observed using spears to hunt bush babies more often than males (though no statistical tests have been performed to find sex differences), though males are more prominent hunters overall (Preutz \& Bertolani 2007).

Spagnoletti et al. (2011) summarized the findings of the extensive work on chimpanzee tool use, noting that females have been observed using probing and stone tools more frequently than males. Female chimps at Gombe have also been observed termite fishing at three times the rate of males (and start termite fishing at 31 months of age rather than 50 months in males) and are more proficient. Marked mother-daughter behavioral transfer in tool use has also been observed in many populations; male tool use behavior is not similar to that of their mother. Females are also more proficient at cracking Coula nuts in the branches of trees (and overall), and cracking Panda nuts (the most difficult for chimpanzees to crack). Some authors have attributed this sex difference as a difference in foraging strategy - females spend more time obtaining reliable foods (like nuts), while males spend more time hunting (and engaging in social activities) (Spagnoletti et al. 2011). Chimpanzees are also one of few non-human primates to use tools for hygienic purposes and to incorporate tools into social interactions. Chimpanzees have been observed to use leaf napkins to wipe foreign material from their hair or to dab at wounds, and leaf clipping (stripping the lamina of the leaf from the rib with the lips in 
order to make a sound) has been known to be used to solicit grooming and copulation, as well as to signal the onset of a male display of dominance (Watts 2008).

Hopkins et al. (2009) demonstrated sex differences in handedness during tool use in chimpanzees, as well as vertical transmission of handedness from mothers to offspring. The authors found that females were statistically significantly more likely to be righthanded than males, and that offspring of right-handed mothers were more likely to be right-handed (and vice versa). They also found that hand preferences were strong enough that left- or ambiguously-handed chimpanzees performed tool dipping tasks (similar to termite fishing) significantly faster with their left hand than their right, and right-handed chimpanzees were significantly faster with their right hand than their left. The authors also had the general finding that female chimpanzees were more successful tool users overall, which supports the majority of research on chimpanzee tool use.

Bonobos have not had as much research attention as chimpanzees regarding tool use, but Gruber et al. (2010) conducted a comparison study of chimpanzees and bonobos. The authors found that female bonobos used tools more often than males (ANOVA: $F$ $(1,15)=8.15, p=.014)$, and that bonobos display a large diversity of tool use behaviors comparable to those of chimpanzees. A few notable exceptions included that bonobos have a much more diverse range of "Play" behaviors than chimpanzees, bonobos use tools for sexual stimulation, and bonobos use tools mainly in social and personal care contexts while chimpanzees use tools mainly for food acquisition. These are not surprising findings, as play and other neotenous behaviors are common in adult bonobos. 
Overall, this study demonstrated the trend towards a female bias in tool use in the Pan genus.

A notable study of bonobo tool use was conducted by Schick et al. (1999), in which the authors attempted to teach Kanzi and his half-sister Panbanisha to make flaked stone tools. This study clearly demonstrated that bonobos have the cognitive capacity to recognize potentially useful tools and modify raw materials into more useful tools, but it also appears highly unlikely that such modification would happen in wild bonobos. Though Kanzi is more proficient at making tools than his sister, it would be unwise to conclude that male bonobos are better toolmakers in general since Kanzi has had more instruction and the sample size is extremely small.

Humans. Lee (1979) conducted fieldwork with about 500 !Kung hunter-gatherers of Botswana for three years, and focused much of his attention on sexual division of labor (especially labor related to hunting and gathering). As is typical of most hunter-gatherer cultures, females focus their energies on gathering foods while males hunt (Lee 1979). The author tracked the number of working days per week in both sexes, and found that men worked a third harder than women (worked 12 out of 28 days versus worked 9 out of 28 days). Though these data seem to contradict the common idea that women engage in the majority of work in hunter-gatherer societies, the gathered food provided by women comprise 70 percent of all calories consumed by the !Kung. The author calculated the proportion of calories over the 28-day period that each day of work provided, and found that one day of gathering provided 0.6 percent of the period's total food, while one day of hunting only provided 0.36 percent of the total food. As another measure, the author 
calculated that one day of gathering produced 12,000 calories, while one day of hunting produced 7,230 calories. Overall, the men produced 860,000 calories in 104.5 days of work (83 days of hunting plus 21.5 days of gathering) and the women and teenage girls produced 1,140,000 calories in 94.5 days of gathering. These measures present a striking picture of !Kung subsistence - though the men worked harder (quantified by days of work), the women produced significantly more calories.

Lee also noted the technology of the !Kung, which is mainly focused on food acquisition and processing. The author splits their technology into four categories: tools for obtaining water, gathering and carrying tools, hunting tools, and food-processing tools. Women predominantly use three of the four categories of tools (obtaining water, gathering and carrying, and food-processing), but the hunting tools used by men are diverse and used more extensively (since they work more days than women). The author also observed work that was not directly related to subsistence, which he referred to as household work or manufacture, maintenance, and repair. He found that men spent an average of 64.29 minutes per day doing this type of work, while women spent 44.92 minutes per day. There did appear to be discrepancies in the type of work done by each sex (though the author did not perform any statistical tests) - men spent 58.95 minutes per day on manufacturing and maintenance work related to subsistence, while women only spent 23.56 minutes per day on such work. Women also spent 18 minutes per day on manufacturing and maintenance work related to housing, while men only spent 3 minutes per day on such work. When childcare and other housework is accounted for, men and women have nearly equivalent work weeks -44.5 hours per week for men, and 40.1 
hours per week for women. Overall, Lee's work indicates that !Kung men and women engage in about the same quantity of work and are approximately equivalent in their tool use, but the sexes vary greatly in the type of work performed and tools used.

There does not appear to be a sex bias in tool use in humans, which is probably due to the cost of gestation and lactation being offset by paternal investment. Humans are one of few species of primates which exhibit appreciable paternal investment, meaning that though females still bear the costs of gestation and lactation like other primates, males offset this cost by provisioning for both the female and her offspring. There are clear differences in the types of tools used and the tasks for which they are needed in traditional hunter-gatherer societies, but both sexes are proficient tool users.

\section{Non-Primate Species}

Dolphins. Bottlenose dolphins have been observed using basket marine sponges as tools to locate food (Smolker et al. 1997, Mann 2009). Smolker et al. (1997) first witnessed the "sponging" behavior, and observed five habitual females and four anomalous (two female, one probably female, and one male) "spongers" over a 13-year period. Mann (2009) also described a female bias in this tool use, as only 6 of the 43 "spongers" she observed were male, and the "sponging" behavior appears to be passed between mothers and daughters. The male "spongers" also had "sponger" mothers, so transmission of the behavior from fathers to offspring appears to be nonexistent. Mann (2009) also noted that for all the "spongers" for whom parentage was known, 100\% had "sponger" mothers as well. However, none of these studies conducted statistical tests to determine sex differences, in spite of describing a female bias. 
"Spongers" carry a sponge over their rostra (also known as a beak) as they probe the sea floor looking for prey - "the sponge is thought to function as a shield by providing protection from the sharp and rough seafloor, and possibly venomous or spiny benthic marine organisms, while dolphins search for and extract prey" (Patterson \& Mann 2011:1). Patterson \& Mann (2011) predicted that the prey the "spongers" were searching for lacked swimbladders (fish with swimbladders give off more acoustic backscatter, which dolphins can locate more easily using echolocation), and they found that $78 \%$ of the prey the dolphins extracted while "sponging" lacked swimbladders. In contrast, only $19 \%$ of the prey caught by non-"spongers" lacked swimbladders. The authors noted that they swimbladderless prey caught by "spongers" were "high-energy, premium foods" (Patterson \& Mann 2011:4) compared to the fish caught by non"spongers."

Otters. Otters are well-documented tool users - they use rocks to crack open mussels, sea urchins, crabs, abalone, and other prey. However, few studies have documented sex differences in otters' tool use behavior. Hall \& Schaller (1964) documented 30 instances of tool use over a 6 day observation period by California sea otters. Otters float on their backs while holding a prey item in one paw and a rock in another, and use the rock to bash they prey item open on their chests. They have also been observed using mussel or abalone shells in the same manner as rocks (or bashed two whole mussels together to achieve the same effect). Females were observed keeping the same stone for several consecutive dives for food and sharing food with their offspring during tool use, leading to prolonged tool-using sessions compared to males. However, 
the authors did not explicitly state they observed a greater number or complexity of tool use behaviors by females rather than males, making it difficult to draw conclusions about sex bias. However, offspring have been observed copying distinct foraging and tool use patterns from their mothers, indicating that female otters are responsible for transmission of tool use behavior (Riedman et al. 1989).

Corvids. Corvids are highly intelligent, and have a brain-to-body size ratio similar to that of chimpanzees (very encephalized by avian standards) (Emery 2004). They are most notable for their incredible memories - corvids make large food caches and can remember where the majority of them are (Clark's nutcrackers cache over 30,000 seeds over a wide area, and can find them up to six months later). Western scrub jays can also remember the types of food they have cached and for how long - experimental manipulation allowing the jays to cache both perishable and nonperishable foods revealed that the birds would recover perishable foods if a short amount of time had passed between cache and recovery, and would recover nonperishable foods if a longer amount of time had elapsed (Grodzinski \& Clayton 2010). New Caledonian crows have not only been observed using tools, but also manufacturing them - they craft hooks out of twigs for poking insect larvae out of trees, and make stepped-cut leaves for probing for prey under leaf detritus (Emery \& Clayton 2004). Corvid foraging behavior has not been studied at length, though they are omnivorous and have been observed making and using some tools for food acquisition. There do not appear to be sex differences in tool use both sexes seem capable and motivated to use tools (Rolando \& Zunino 1992). 
Some corvids have also been observed engaging in aggressive behaviors that led Balda (2007) to believe they may be using tools as weapons - a Steller's Jay and an American Crow fought over a feeding platform, and the jay deliberately broke a twig from a branch and lunged towards the crow with the pointed end. The jay missed, and the crow lunged back at the jay, causing the jay to drop the twig. The crow then picked up the twig and lunged back at the jay, flying after the jay with the twig still in its mouth after the jay attempted to flee. It is unclear whether this encounter truly constitutes aggression with a weapon, but it does seem to indicate complex tool-using behavior.

It has been proposed that the prolific tool use observed in both primates and corvids is the result of convergent evolution (Emery \& Clayton 2004; Seed et al. 2009). Emery \& Clayton (2004) proposed that apes and corvids share four nonverbal cognitive tools which form the basis of complex cognition: causal reasoning, flexibility, prospection, and imagination. The authors close by suggesting these shared traits are not the result of convergent brain evolution (corvids lack a prefrontal cortex), but rather convergent mental evolution. Albiach-Serrano et al. (2012) attempted to test the convergent evolution hypothesis by presenting apes (gorillas, chimpanzees, bonobos, and orangutans) and corvids (crows and ravens) with the same patterned-string tasks. The apes outperformed the corvids overall, completing a greater number of more difficult puzzles at a faster rate; one interesting finding was that the apes were better at solving a "real" task than a manufactured one, while the corvids had the same success rate with both types of puzzles. The animals had to choose the correct arm of a cross to "pull" to obtain a food reward - the "real" puzzle had paper strips that could actually be pulled, 
while the manufactured puzzle had stripes painted on the board (the correct arm had the food reward attached to the end, so the reward would come off the board with the paper strip). The authors hypothesized that the apes had some causal understanding of the tasks, while the corvids may have been using spatial or arbitrary cues.

Overall Analysis

A regression was performed on the body mass versus basal metabolic rate (BMR) data (Figure 1), and the residuals were calculated. A t-test was performed on the mean residuals for female bias versus no bias species, and no significant differences were found $(t 1.073=0.771, p=.574)($ Table 1$)$. A regression was performed on the male versus female energetic cost of reproduction data (Figure 2), and the residuals were calculated. A one-way ANOVA performed on the mean residuals for each tool use bias category, and no significant differences were found $(F 2,9=0.025, p=.976)$ (Table 2$)$. Two of the three female biased tool use species had greater female costs of reproduction (excepting bonobos). The data used to perform statistical analyses can be found in Table 3. 


\section{DISCUSSION}

The general analysis revealed that female bonobos, chimpanzees, and dolphins use tools more proficiently than males; baboons, corvids, gibbons, gorillas, humans, orangutans, otters, macaques, and tamarins have an unclear pattern or no sex bias to tool use, and capuchin males use tools more proficiently than females. There were no statistically significant differences in BMR, body mass, or energetic costs of reproduction between tool use bias categories, and the female bias species do not cluster together on the regressions (Figure 1, Figure 2). Thus, it appears that female bias in tool use probably cannot be explained by ecological or physiological differences between those species (bonobos, chimpanzees, and dolphins) and the species in other bias categories. Capuchin males appear to be more effective tool users due to strength and body size sex differences - female capuchins cannot lift stones heavy enough (or throw them with enough force) to effectively crack nuts (Spagnoletti et al. 2011).

None of the species with female tool use bias (bonobos, chimpanzees, and dolphins) would be classified as female-bonded groups according to Wrangham's (1980) criteria, so his model could not be tested. However, in at least four of the species examined (bonobos, chimpanzees, dolphins, and otters), researchers observed females passing tool use behaviors among themselves, especially between mothers and daughters. These four species include the three female-biased tool users, which lends some support to Wrangham's idea about ecological variables impacting social systems. Though none of the aforementioned species are female-bonded, they do display some characteristics of 
social tolerance, as described by van Schaik et al. (1999). Darwin's (1871/1952) idea that tool use drove intelligence is not supported by these data - the species that use tools in the wild are more intelligent than those that do not, even though some of the lessintelligent species can be taught to use tools in captivity. It appears that animals must have a minimum cognitive capacity in order for tool use to develop, meaning that tool use is a byproduct rather than a driving force of the evolution of intelligence.

One interesting finding was that some species appear to "naturally" use tools in captivity (ex. orangutans) or quickly learn to use them during experimental manipulations (ex. tamarins) but have not been observed using them in the wild. There are a few characteristics of captivity that might contribute to this - animals might find themselves in much closer contact with a much greater number of other members of their species than they would in the wild (like the solitary orangutans), they might imitate humans or other primates they would normally never have contact with in the wild, they may have access to novel materials or ready-made tools in captivity, or they may have more free time (the captive diet would reduce the amount of time the animal would normally spend foraging). Again, animals must bypass a minimum cognitive ability in order to use tools certainly, not all animals given the opportunity to interact with tools would use them in a meaningful way.

Sexual dinichism or other sexual division of labor observed in human populations does not appear to be affected by any variable tested in this paper. van Schaik et al. (1999) explored several theories regarding the evolution of tool use in hominids, including manual dexterity, intelligence, and social tolerance. Though this paper did not 
examine social tolerance, the studies of non-primate species seem to complicate the roles of manual dexterity and intelligence in tool use. Neither corvids nor dolphins are particularly dexterous, and none of the species are as intelligent as primates (though all are very encephalized when compared to more closely-related species); yet, all three species are skilled tool users. The authors proposed that the great increase in intelligence during hominid evolution or an increase in social tolerance probably best explains the complexity of our tool use behavior, but the causes of the prevalence of sexual division of labor (and tool use) in human populations is still unclear.

One confusing variable in this analysis is the unreliability of reports of tool use in the wild - with the exception of chimpanzees, humans, corvids, dolphins, and otters, the evidence for natural tool use and manufacture is limited. However, experimental manipulations with the other species suggest that most primates have the cognitive capacity to recognize the potential utility of tools, especially for food acquisition or processing. Another limiting factor to this research is that the majority of the studies found were not focused on sex differences in tool use - the author had to pick them out from data on individual animals or from the authors' described observations. The sample sizes of these studies were also usually small (which is understandable, given the practical considerations of conducting experiments or recording observations of large, intelligent, and highly mobile organisms), which is not ideal when attempting to synthesize information across several species.

One way to improve the sex differences in energetic costs of reproduction would be to quantify paternal investment and add it in to the calculations - currently, the 
calculations assume no paternal investment. A possible venue for future study would be to construct a measure of the utility or efficiency of various tools used and manufactured by different animals - it would be useful to quantify tool utility when making crossspecies comparisons. It might also be useful to explore van Schaik et al.'s (1999) theory of social tolerance along with Wrangham's (1980) theory of female bonded social groups in relation to sexual dinichism in human tool use. Another interesting modification to current studies of primate tool use would be to replicate the natural conditions in which some primates use tools (i. e. chimpanzees) when experimenting with primates that don't use tools in the wild (i. e. gibbons or tamarins) instead of giving them complicated tools like rakes - providing the animals with similar tools to wild tool-users (ex. hammer and anvil rocks and a pile of nuts) would make the studies more comparable with naturalistic observations. 


\section{APPENDIX}

\section{FIGURES}

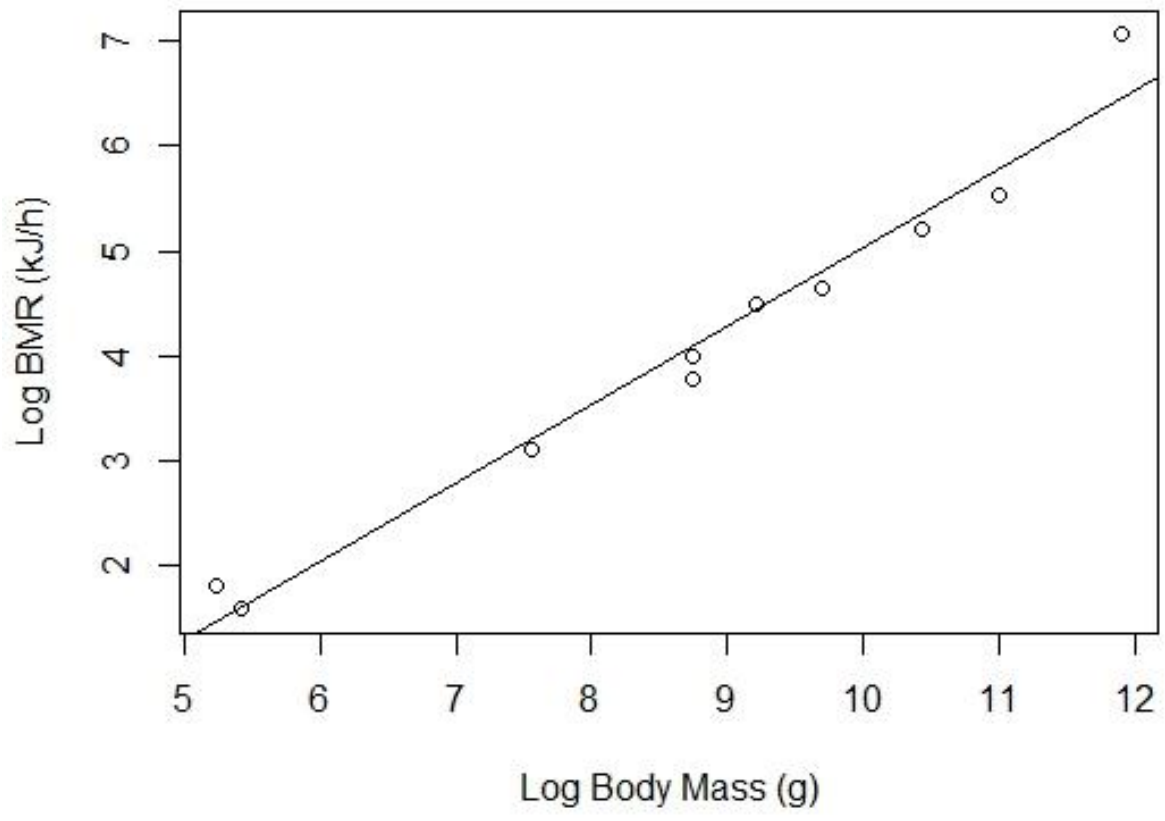

Figure 1. The relationship between body mass and basal metabolic rate (BMR). Points above the line indicate higher BMR than expected for body mass, and points below the line indicate lower BMR than expected for body mass. Bonobos, capuchins, and gorillas have been omitted. 


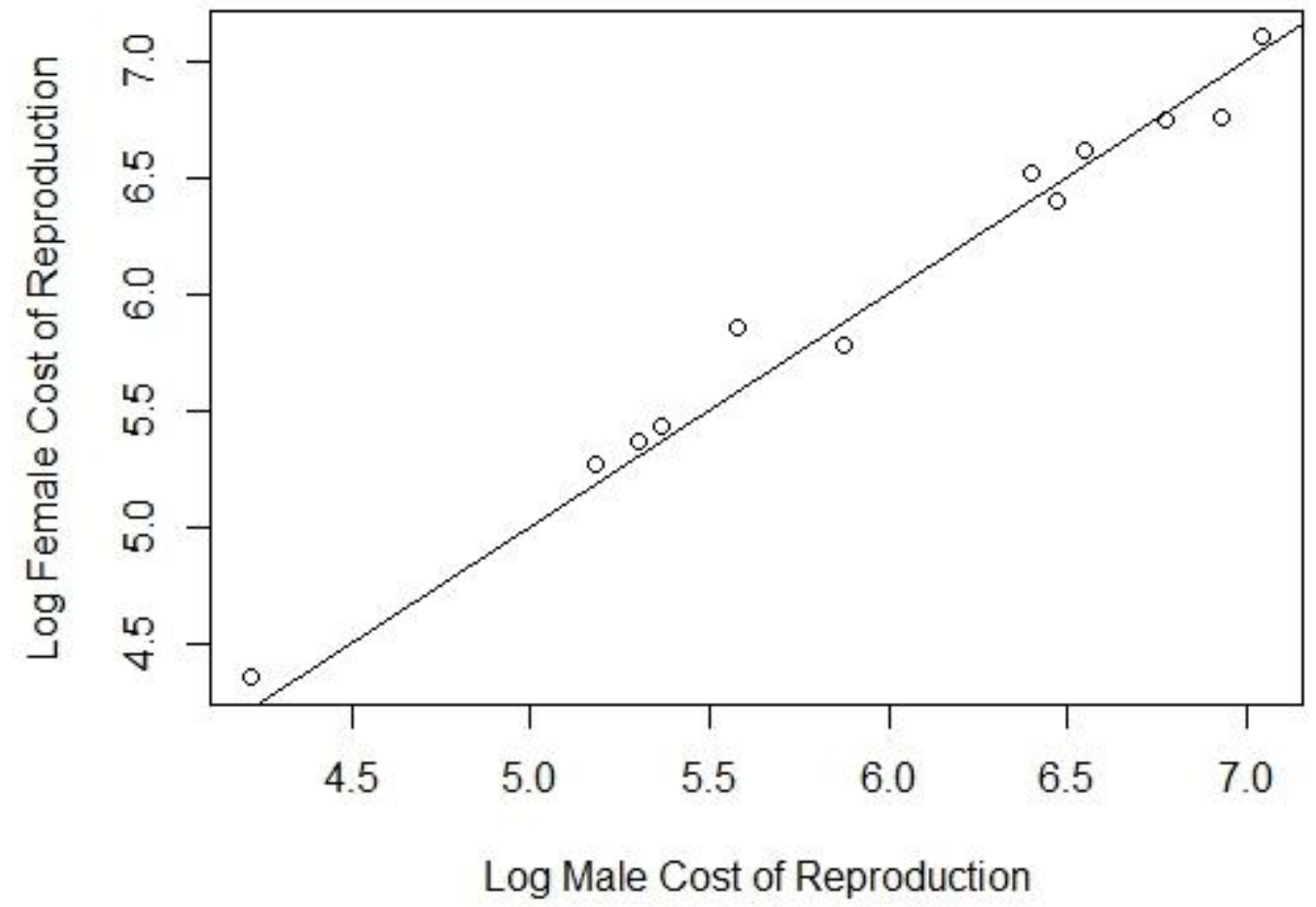

Figure 2. Comparison of male and female energetic cost of reproduction. Points above the line indicate higher female energetic costs, and points below the line indicate higher male energetic costs. Corvids have been omitted. 


\section{TABLES OF STATISTICS}

Table 1. Mean residuals and t-test results for female and no tool use bias species for body mass versus BMR. Bonobos, capuchins, and gorillas have been omitted.

\begin{tabular}{ccccc}
\hline \hline Tool Use Bias & Mean Residual & $t$ & df & $p$ \\
\hline Female & 0.236 & 0.771 & 1.07 & 0.574 \\
None & -0.059 & & & \\
& & & & \\
\hline \hline
\end{tabular}


Table 2. Mean residuals and one-way ANOVA results across tool use bias species for male versus female energetic costs of reproduction. Corvids have been omitted.

\begin{tabular}{ccccc}
\hline \hline Tool Use Bias & Mean Residual & $F$ & df & $p$ \\
\hline Female & -0.013 & 0.025 & 2,9 & 0.976 \\
None & 0.003 & & & \\
Male & 0.011 & & & \\
\hline \hline
\end{tabular}


Table 3. Basal metabolic rate (BMR), tool use bias, daily energy expenditure (DEE), cost of reproduction (COR), and body mass data for the thirteen species of interest. Tool use bias is indicated as female (F), male (M), or none (N). Missing data (BMR and COR) are indicated by N/A.

\begin{tabular}{|c|c|c|c|c|c|c|c|}
\hline \multirow{2}{*}{ Species } & \multirow[b]{2}{*}{$\begin{array}{c}\text { BMR } \\
(\mathrm{kJ} / \mathrm{h})\end{array}$} & \multirow[b]{2}{*}{$\begin{array}{l}\text { Tool Use } \\
\text { Bias }\end{array}$} & \multicolumn{5}{|c|}{ Log } \\
\hline & & & $\begin{array}{c}\text { Male DEE } \\
(\text { kcal })\end{array}$ & $\begin{array}{c}\text { Female DEE } \\
(\text { kcal })\end{array}$ & $\begin{array}{c}\text { Female } \\
\text { CoR } \\
(\text { kcal })\end{array}$ & $\begin{array}{c}\text { Log Male } \\
\text { COR } \\
(\text { kcal })\end{array}$ & $\begin{array}{c}\text { Mean Mass } \\
(\mathrm{g})\end{array}$ \\
\hline Pan troglodytes & 182.4 & $\bar{F}$ & 1754.8 & 1470.4 & 6.548 & 6.615 & 33900 \\
\hline Tursiops & & & & & & & \\
\hline truncates & 1163.7 & F & 7713.1 & 7060.9 & 7.046 & 7.104 & 148600 \\
\hline Pan paniscus & $\mathrm{N} / \mathrm{A}$ & F & 1688.6 & 1196.3 & 6.471 & 6.399 & $\mathrm{~N} / \mathrm{A}$ \\
\hline Cebus capucinus & $\mathrm{N} / \mathrm{A}$ & $\mathrm{M}$ & 254.50 & 212.74 & 5.304 & 5.369 & $\mathrm{~N} / \mathrm{A}$ \\
\hline Pongo pygmaeus & 103.4 & $\mathrm{~N}$ & 3341.3 & 1632.3 & 6.932 & 6.762 & 16200 \\
\hline Papio papio & 54.6 & $\mathrm{~N}$ & 1043.4 & 620.42 & 5.876 & 5.779 & 6230 \\
\hline Corvus monedula & 6.19 & $\mathrm{~N}$ & 72.946 & 72.946 & $\mathrm{~N} / \mathrm{A}$ & $\mathrm{N} / \mathrm{A}$ & 188 \\
\hline Hylobates lar & 22.4 & $\mathrm{~N}$ & 344.28 & 344.28 & 5.576 & 5.851 & 1900 \\
\hline Homo sapiens & 255.1 & $\mathrm{~N}$ & 1859.1 & 1781.1 & 6.399 & 6.524 & 60500 \\
\hline Lutra lutra & 90.4 & $\mathrm{~N}$ & 575.19 & 456.36 & 5.179 & 5.267 & 10000 \\
\hline $\begin{array}{c}\text { Macaca mulatta } \\
\text { Sanguinas }\end{array}$ & 43.8 & $\mathrm{~N}$ & 431.39 & 325.99 & 5.367 & 5.433 & 6230 \\
\hline geoffroyi & 4.89 & $\mathrm{~N}$ & 49.729 & 49.729 & 4.219 & 4.349 & 225 \\
\hline Gorilla gorilla & $\mathrm{N} / \mathrm{A}$ & $\mathrm{N}$ & 4149.2 & 2738.3 & 6.775 & 6.749 & $\mathrm{~N} / \mathrm{A}$ \\
\hline
\end{tabular}




\section{REFERENCES}

Albiach-Serrano, A., Bugnyar, T., \& Call, J. 2012. Apes (Gorilla gorilla, Pan paniscus, $P$. troglodytes, Pongo abelii) versus corvids (Corvus corax, C. corone) in a support task: The effect of pattern and functionality. Journal of Comparative Psychology, 126, 355-367.

Balda, R. P. 2007. Corvids in combat: With a weapon? The Wilson Journal of Ornithology, 119, 100-102.

Beck, B. B. 1973. Cooperative tool use by captive Hamadryas baboons. Science, 182, 594-597.

Beck, B. B. 1980. Animal tool behavior: The use and manufacture of tools by animals. New York: Garland Press.

Boesch, C., \& Boesch, H. 1990. Tool use and tool making in wild chimpanzees. Folia Primatologica, 54, 86-99.

Borgia, G., \& Mueller, U. 1992. Bower destruction, decoration stealing and female choice in the spotted bowerbird Chlamydera maculata. Emu, 92, 11-18.

Breuer, T., Ndoundou-Hockemba, M., \& Fishlock, V. 2005. First observation of tool use in wild gorillas. PLOS Biology, 3, 2041-2043.

Brown, C. 2012. Tool use in fishes. Fish and Fisheries, 13, 105-115.

Cunningham, C. L., Anderson, J. R., \& Mootnick, A. R. 2006. Object manipulation to obtain a food reward in hoolock gibbons, Bunopithecus hoolock. Animal Behaviour, 71, 621-629.

Cunningham, C., Anderson, J., \& Mootnick, A. 2011. A sex difference in effect of prior experience on object-mediated problem-solving in gibbons. Animal Cognition, 14, 599-605.

Darwin, C. 1952. The descent of man, and selection in relation to sex. In Great Books of the Western World: 49. Darwin. (Ed. by R. M. Hutchins), 253-597. Chicago:

Encyclopedia Brittanica, Inc. (Original work published 1871)

de A. Moura, A. C., \& Lee, P. C. 2010. Wild capuchins show male-biased feeding tool use. International Journal of Primatology, 31, 457-470. 
Dodds, P. S., Rothman, D. H., \& Weitz, J. S. 2001. Re-examination of the "3/4-law" of metabolism. Journal of Theoretical Biology, 209, 9-27.

Emery, N. J. 2004. Are corvids 'feathered apes'?: Cognitive evolution in crows, jays, rooks, and jackdaws. In: Comparative Analysis of Mind (Ed. by S. Watanabe), pp. 1-33. Tokyo: Keio University Press.

Emery, N. J. \& Clayton, N. S. 2004. The mentality of crows: Convergent evolution of intelligence in corvids and apes. Science, 306, 1903-1907.

Estes, J. A. \& Palmisano, J. F. 1974. Sea otters: Their role in structuring nearshore communities. Science, 185, 1058-1060.

Furuichi, T., Idani, G., Ihobe, H., Kuroda, S., Kitamura, K., Mori, A., Enomoto, T., Okayasu, N., Hashimoto, C., \& Kano, T. 1998. Population dynamics of wild bonobos (Pan paniscus) at Wamba. International Journal of Primatology, 19, 1029-1043.

Galef, B. G. Jr. 1992. The question of animal culture. Human Nature, 3, 157-178.

Gomendio, M. 1990. The influence of maternal rank and infant sex on maternal investment trends in rhesus macaques: Birth sex ratios, inter-birth intervals and suckling patterns. Behavioral Ecology and Sociobiology, 27, 365-375.

Grodzinski, U., \& Clayton, N. S. 2010. Problems faced by food-caching corvids and the evolution of cognitive solutions. Philosophical Transactions of the Royal Society B, 365, 977-987.

Gruber, T., Clay, Z., \& Zuberbühler, K. 2010. A comparison of bonobo and chimpanzee tool use: Evidence for a female bias in the Pan lineage. Animal Behaviour, 8, 1023-1033.

Gumert, M. D., Hoong, L. K., \& Malaivijitnond, S. 2011. Sex differences in the stone tool-use behavior of a wild population of Burmese long-tailed macaques (Macaca fascicularis aurea). American Journal of Primatology, 73, 1239-1249.

Hall, K. R. L., \& Schaller, G. B. 1964. Tool-using behavior of the California sea otter. Journal of Mammalogy, 45, 287-298.

Hauser, M. D. 1997. Artifactual kinds and functional design features: what a primate understands without language. Cognition, 64, 285-308. 
Hauser, M., Pearson, H., \& Seelig, D. 2002. Ontogeny of tool use in cottontop tamarins, Saguinus oedipus: Innate recognition of functionally relevant features. Animal Behaviour, 64, 299-311.

Hopkins, W.D., Russell, J.L., Schaeffer, J.A., Gardner, M., \& Schapiro, S.J. 2009. Handedness for tool use in captive chimpanzees (Pan troglodytes): sex differences, performance, heritability and comparison to the wild. Behaviour, 146, 1463-1483.

Key, C., \& Ross, C. 1999. Sex differences in energy expenditure in non-human primates. Proceedings of the Royal Society of London B, 266, 2479-2485.

Lee, R. B. 1979. The !Kung San: Men, Women, and Work in a Foraging Society. Cambridge: Cambridge University Press.

Lemasson, A., Palombit, R. A., \& Jubin, R. 2008. Friendships between males and lactating females in a free-ranging group of olive baboons (Papio hamadryas anubis): Evidence from playback experiments. Behavioral Ecology and Sociobiology, 62, 1027-1035.

Mann, J., Connor, R. C., Barre, L. M., \& Heithaus, M. R. 1999. Female reproductive success in bottlnose dolphins (Tursiops sp.): Life history, habitat, provisioning, and group-size effects. Behavioral Ecology, 11, 210-219.

Mann, J. 2009. Tool use in dolphins. Australasian Science, 30, 20-22.

McGrew, W. C. 1992. Chimpanzee Material Culture: Implications for Human Evolution. Cambridge: Cambridge University Press.

McNab, B. K. 2008. An analysis of the factors that influence the level and scaling of mammalian BMR. Comparative Biochemistry and Physiology, Part A, 151, 5-28.

McNab, B. K. 2009. Ecological factors affect the level and scaling of avian BMR. Comparative Biochemistry and Physiology, Part A, 152, 22-45.

Monson, D. H., Estes, J. A., Bodkin, J. L., \& Siniff, D. B. 2000. Life history plasticity and population regulation in sea otters. Oikos, 90, 457-468.

Nakamichi, M. 2004. Tool-use and tool-making by captive, group-living orangutans (Pongo pygmaeus abelii) at an artificial termite mound. Behavioural Processes, 65, 8793.

Oakley, K. P. 1957. Man the tool-maker. Chicago: University of Chicago Press. 
Osvath, M., \& Osvath, H. 2008. Chimpanzee (Pan troglodytes) and orangutan (Pongo abelii) forethought: self-control and pre-experience in the face of future tool use. Animal Cognition, 11, 661-674.

Patterson, E. M., \& Mann, J. 2011. The ecological conditions that favor tool use and innovation in wild bottlenose dolphins (Tursiops sp.). PLoS ONE, 6, 1-7.

Preutz, J. D. \& Bertolani, P. 2007. Savanna chimpanzees, Pan troglodytes verus, hunt with tools. Current Biology, 17, 412-417.

R Development Core Team. 2011. R: A language and environment for statistical computing, Vienna, Austria: R Foundation for Statistical Computing. ISBN 3-900051-070, URL http://www.R-project.org/.

Riedman, M. L., Staedier, M. M., Estes, J. A., \& Hrabrich, B. 1989. The transmission of individually distinctive foraging strategies from mother to offspring in sea otters (Enhydra lutris). In Eighth Biennial Conference on the Biology of Marine Mammals. Pacific Grove, CA.

Rolando, A., \& Zunino, M. 1992. Observations of tool use in corvids. Ornis Scandinavica, 23, 201-202.

Ross, C. 1992. Basal metabolic rate, body weight and diet in primates: An evaluation of the evidence. Folia Primatologica, 58, 7-23.

Savage, A., Shideler, S. E., Soto, L. H., Causado, J., Giraldo, L. H., Lasley, B. L., \& Snowdon, C. T. 1997. Reproductive events of wild cotton-top tamarins (Sanguinas oedipus) in Columbia. American Journal of Primatology, 43, 329-337.

Schick, K. D., Toth, N., Garufi, G., Savage-Rumbaugh, E. S., Rumbaugh, D., \& Sevcik, R. 1999. Continuing investigations into the stone tool-making and tool-using capabilities of a Bonobo (Pan paniscus). Journal of Archaeological Science, 26, 821-832.

Seed, A., Emery, N., \& Clayton, N. 2009. Intelligence in corvids and apes: A case of convergent evolution? Ethology, 115, 401-420.

Smolker, R. Richards, A., Connor, R., Mann, J., \& Berggren, P. 1997. Sponge carrying by dolphmeins (Delphinidae, Tursiops sp.): A foraging specialization involving tool use? Ethology, 103, 454-465.

Spagnoletti, N., Visalberghi, E., Ottoni, E., Izar, P., \& Fragaszy, D. 2011. Stone tool use by adult wild bearded capuchin monkeys (Cebus libidinosus): Frequency, efficiency and tool selectivity. Journal of Human Evolution, 61, 97-107. 
Stoinski, T. S. \& Beck, B. B. 2001. Spontaneous tool use in captive, free-ranging golden lion tamarins (Leontopithecus rosalia rosalia). Primates, 42, 319-326.

Trivers, R. 1972. Parental investment and sexual selection. In Sexual Selection and the Descent of Man: 1871-1971 (Ed. by B. G. Campbell), 136-179. Chicago: Aldine Transaction.

van Lawick-Goodall, J., van Lawick, H., \& Packer, C. 1973. Tool-use in free-living baboons in the Gombe National Park, Tanzania. Nature, 241, 212-213.

van Schaik, C. P., Deaner, R. O., \& Merrill, M. Y. 1999. The conditions for tool use in primates: Implications for the evolution of material culture. Journal of Human Evolution, 36, 719-741.

Watts, D. P. 2008. Tool use by chimpanzees at Ngogo, Kibale National Park, Uganda. International Journal of Primatology, 29, 83-94.

Westergaard, G. C. 1992. Object manipulation and the use of tools by infant baboons (Papio cynocephalus anubis). Journal of Comparative Psychology, 106, 398-403.

Wittiger, L., \& Sunderland-Groves, J.L. 2007. Tool use during display behavior in wild Cross River gorillas. American Journal of Primatology, 69, 1307-1311.

Wrangham, R. W. 1980. An ecological model of female-bonded primate groups. Behaviour, 75, pp. 262-300. 